\title{
МЕТОДЫ МОЛЕКУЛЯРНОЙ СПЕКТРОСКОПИИ В АНАЛИЗЕ
}

Камнев А.А.

Федеральное государственное бюджетное учреждение науки Институт биохимии и физиологии растений и микроорганизмов Российской академии наук, Саратов aakamnev@ibppm.ru, a.a.kamnev@mail.ru

DOI: 10.26902/ASFE-11_11

Использование различных методов молекулярной спектроскопии в анализе в широком смысле позволяет не только решать задачи обнаружения и идентификации соединений, но также изучать особенности молекулярной структуры (и фиксировать ее изменения), в том числе в сложных надмолекулярных системах - вплоть до клеток микроорганизмов и образцов тканей высших организмов. В данной лекции будут обсуждены примеры анализов, в основном проводившихся в нашей научной группе, с помощью методов колебательной спектроскопии (ИК-фурье-спектроскопии (ИКФС; в различных режимах измерений); спектроскопии комбинационного рассеяния, СКР) [1-4] и мёссбауэровской спектроскопии (ядерный гамма-резонанс, ЯГР) [4-6].

Методы ИКФС и СКР позволяют получить из экспериментальных спектров информацию о характерных колебаниях присутствующих в образце функциональных групп; при этом интенсивности всех колебаний пропорциональны содержанию этих групп. Заметим, что при изучении сложных (био)органических систем методом ИКФС для получения качественных спектров и их адекватной интерпретации необходимо учитывать ряд методологических особенностей $[1,2,7]$. Хотя селективность ИКФС и СКР относительно невысока (т.к. однотипные функциональные группы дают сходные полосы колебаний в различных соединениях), это вполне компенсируется высокой информативностью спектров. Так, помимо наличия нескольких видов колебаний у сложных групп (дающих обычно несколько полос в разных областях частот), энергия колебаний зависит от межмолекулярных и внутримолекулярных взаимодействий, что проявляется на спектрах в виде характерных сдвигов полос или их расщепления.

Спектроскопия ЯГР основана на резонансном поглощении $\gamma$-излучения ядрами определенных изотопов; самым распространенным является ${ }^{57} \mathrm{Fe}$ (его содержание в природном железе $2.2 \%$ ). Этот метод (по сути, ядерно-химический) дает уникальную информацию о химическом состоянии атома (катиона; например, ${ }^{57} \mathrm{Fe}$ ), а также о его непосредственном молекулярном окружении; именно поэтому он занимает достойное место среди методов молекулярной спектроскопии [5]. Хотя его история насчитывает всего 6 десятилетий, он уже давно применяется во всех областях материаловедения - от анализа металлов и сплавов до Fе-содержащих белков, включая ферменты $[5,6]$.

Следует отметить, что во многих случаях методы молекулярной спектроскопии позволяют проводить неразрушающий анализ образцов in situ и даже in vivo [1, 2, 4-7].

\section{Список литературы}

1. Tugarova A.V., Dyatlova Yu.A., Kenzhegulov O.A., Kamnev A.A. Spectrochim. Acta Part A: Mol. Biomol. Spectrosc. 252 (2021) 119458.

2. Kamnev A.A., Dyatlova Yu.A., Kenzhegulov O.A., Vladimirova A.A., Mamchenkova P.V., Tugarova A.V. Molecules 26 (2021) 1146.

3. Tugarova A.V., Mamchenkova P.V., Khanadeev V.A., Kamnev A.A. New Biotechnol. 58 (2020) 17-24.

4. Kamnev A.A., Tugarova A.V., Shchelochkov A.V., Kovács K., Kuzmann E. Spectrochim. Acta Part A: Mol. Biomol. Spectrosc. 229 (2020) 117970.

5. Камнев А.А., Тугарова А.В. Успехи химии 90 (2021) https://doi.org/10.1070/RCR5006.

6. Kamnev A.A., Tugarova A.V. Talanta 174 (2017) 819-837.

7. Kamnev A.A., Tugarova A.V., Dyatlova Yu.A., Tarantilis P.A., Grigoryeva O.P., Fainleib A.M., De Luca S. Spectrochim. Acta Part A: Mol. Biomol. Spectrosc. 193 (2018) 558-564. 